\title{
USING MATERIALS BY MODULE IN TEACHING MATHS-TEACHING METHODOLOGY MODULE FOR MATHS STUDENTS AT LAO TEACHER TRAINING COLLEGES
}

\section{Trung Tran ${ }^{1,+}$, Done Sophida ${ }^{2}$}

\author{
Article History \\ Received: November 11, 2019 \\ Accepted: January 20, 2020 \\ Published: March 30, 2020
}

\section{Keywords \\ Materials by module, maths teaching methodology, teacher training college}

\author{
${ }^{1}$ Vietnam Academy for Ethnic Minorities; \\ ${ }^{2}$ Dongkhamsang Teacher Training College, Lao \\ ${ }^{+}$Corresponding author • Email: trungt1978@gmail.com
}

\begin{abstract}
Among popular teaching approaches, teaching by module is attracting educationers. In education, the module approach is linked to the teaching technology ideology, which is a modern way of structuring or organizing the compilation of teaching content so that the training program becomes more flexible and adapted to the diverse learning organization. On the basis of research on the training program for Maths students at Lao teacher training colleges and theoretical research on modules; teaching modules; teaching materials by modules, from the materials; subject entitled Maths Teaching Methodology is designed. The article mentions the use of this material in teaching Maths Teaching Methodology module for Maths students at Lao teacher training colleges.
\end{abstract}

\section{INTRODUCTION}

The philosophy of education for the $21^{\text {st }}$ century demonstrates the central idea that "lifelong learning" is fundamental, based on the overall goals of learning: learning to know, learning to work, learning to cohabiting and learning to be human towards building a learning society (Unesco, 1996). Lao People's Democratic Republic is in the period of accelerating education innovation and development, requiring society to create highly qualified human resources. In 2015, Lao Ministry of Education and Sports determined top priorities to improving the quality of teaching and learning, including renovating the curriculum, contents, teaching and learning methods, improving the quality of teaching staff, strengthening schools' infrastructure and promoting the learners' creativity.

The Lao Human Resource Development Strategy from 2006 to 2015 includes four directions: 1) Enhancing the teaching content in the country's curriculum which lasts 12 years; 2) Encouraging and expanding learners' opportunities, improving the quality and link of education; 3) Organizing educational science strategies and action plans for educational sciences; 4) Expanding technical and vocational training schools. The education and training system of Lao is increasingly improving the quality of human resource training with special attention paid to highly qualified science and technology human resources, good business people and skilled workers directly contribute to improving the competitiveness of the economy, speeding up the implementation of education universalization. It also aims at innovating objectives, content, methods, educational programs at all levels and training levels; developing teaching staff to meet the requirements of both increasing the scale and improving the quality, renewing teaching methods, managing education, creating a legal basis and promoting internal resources for educational development.

At present, one of the approaches being concerned is to organize teaching by module. In education, the module approach is linked to the teaching technology ideology, which is a modern way of structuring or organizing the compilation of teaching content so that the training program becomes flexible, easy and suitable for diverse learning organizations. The teaching module has many levels: The large module consists of secondary modules and the secondary module consists of small modules. Each teaching module is an effective means of self-study because it corresponds to a specific teaching topic, divided into small sections with the goal of knowledge standards, specific skills and testing methods, corresponding rating. In each lesson, after finishing the small module, students will study the next small module and complete learning tasks. Due to the relative independence of the teaching content, lecturers can "assemble" and "remove" the modules to build diverse, rich teaching programs to meet differentiated and individualized teaching requirements, and students under the guidance of lecturers can learn at their own pace, suitable for themselves. The article mentions the use of materials by module in teaching module Maths-teaching methodology for Maths students of Lao teacher training colleges. 


\section{LITERATURE REVIEW}

In 1920s, module structured programs were used in the United States to quickly and efficiently meet the job requirement in production lines (from 2 to 3 days), learners were familiar with the goals of the job and trained on the line. When a job is transferred (other job content), the worker must go through a similar short course. This method and form of training has been quickly popularized and widely applied in the United Kingdom and some European countries owing to its practicality, time-saving and training costs. It is easy to see that this is a type of training by module in the American style: "In essence, direct and effective" (Espiritu, 1980). At the Center for Vocational Education of Ohio University Institute in the United States, people have used the pedagogical training fostering system for teachers, supplementary program "competence for teachers" was structured from 12-100 modules. The typical feature of module program in the US is that it is stratified very tightly, mainly 2 levels with the basic training modules and subsidiary module.

In France, module courses were held after the $2^{\text {nd }}$ World War in coal mines regions. But the difference is that American workers are trained to meet production lines; in France, it is to create jobs for miners. Due to the unemployment in coal mines region, the courses are "full" and "highly integrated" (Jab Vongthavy, 2014). In Sweden, the training program for logging workers is structured according to the sequence and basic content through training modules. The training system in Sweden was applied in the 1950s, but so far it has not been completed. This shows that showing module limit and content is a very complex job, determining the effectiveness of training by module (Havinghurst, 1973).

The module structured program and training methods by module have been developed and widely applied in many countries all over the world. The development of program structure by module in each country, in each field and each industry has been researched and applied on the basis of theory and practice of each country. Studies show that the process of organizing training by module in countries has had certain effects. In general, the studies have focused on the most basic and general issues about the method of teaching mathematics to develop human resources. So far, there has few studies on developing materials by module in teaching pedagogical students in Lao. This is the problem that needs to be studied to contribute to training students as high-quality, capable human resources to meet the requirements of social and educational development of the country.

\section{METHODS AND RESULTS}

\subsection{Research methods}

Theoretical research methods were applied to analyze and synthesize of theoretical basis; Practical investigation was used to study practice; Summarizing experience and applying methods were used to show orienting solutions, proposing measures and elaborating implementation steps.

\subsection{Research results}

\subsubsection{Teaching materials by module}

In education, the module approach is to structure or organize the compilation of teaching content so that the training program becomes more flexible and easily adapted to the diverse learning activities of learners.

According to Phan Trong Ngo (2005), in teaching, the term module is used to refer to a unit of knowledge or a system of skills (in term of practice of intelligence), which is relatively complete and can be combined with knowledge or other skills, forming a complete system on a larger scale.

According to Nguyen Quang Uan (2010), in teaching, the module as a relatively independent unit of the curriculum, is specially structured to guide learning according to the defined goals of the teaching process. The teaching module covers the specific learning content in relation to the various components of the teaching process: objectives, methods and assessment tools.

Therefore, it can be understood that teaching module is a unit of the curriculum, containing the goals, content, teaching methods and assessment tools of learning outcomes, these factors are closely related. The teaching module has many levels: the large module consists of secondary modules and the secondary module consists of small modules. In the process of teaching Maths at pedagogical schools, it is necessary to aim to help students self-study, they will be more convenient when self-study with instructional materials by module. Each teaching module is an effective means of selfstudy because it corresponds to a specific teaching topic, divided into small sections with the goal of knowledge standards, specific skills and corresponding assessment tests. With each lesson, after finishing the small module, students will learn to the next small module so that they can complete the task of learning and gain knowledge. 
Teaching module has many levels. Large modules and secondary teaching modules are often used to design teaching programs. With small modules, self-study materials are convenient for students to self-study effectively. The concept of teaching module, besides meaning as a unit of curriculum, also demonstrates the characteristics of the design and compilation of teaching materials, contributing to the innovation of teaching methods.

\subsubsection{Objectives of Maths teaching methodology module for Maths students of Lao teacher training colleges}

In the training program, after completing this subject, students can understand and apply basic and modern knowledge and skills, meeting social requirements in the study of teaching methods, curricula and textbooks of mathematics in high school, grasping the standards of knowledge and skills.

In terms of knowledge, students need to understand the concepts, properties, formulas, theories and methods of teaching mathematics in high school. Understand the basic formation and development of some mathematical concepts in the program such as Algebra, Geometry, Trigonometry, etc., new issues, difficult issues and need to be noted in the textbook program Maths subjects from grades 6 to 12 .

In terms of skills, students need following skills: 1) Know how to apply knowledge to research teaching methods, textbook programs in high schools; 2) Know how to apply Maths to practice; 3) Research and analyze mathematics programs in high school to understand standard knowledge, basic skills of each chapter and the program of each grade; 4) Understand the formation and development of some basic mathematical concepts and definitions in the program; 5) Know how to choose teaching methods, facilities, design teaching plans for specific lessons.

In terms of attitudes, students have a sense of seriousness in learning, prepare well the theory, exercises and collectibles, accumulate self-study and self-study experiences to study well the subjects facilities and specialized subjects. 3.2.3. Structure of the material by module in Maths Teaching Methodology module for Math students of Lao pedagogical colleges

According to the framework program of the Lao Ministry of Education and Sports designed for students in Mathematics, teacher training colleges put the content of the Maths Teaching Methodology into teaching and there are differences when designing detailed outline for this subject. Teaching materials by modules of this subject is designed into modules, corresponding to the knowledge sections (chapters). In the modules, each sub-module is arranged in a way that is relatively independent from the knowledge units in the module, with content suitable for learners, forming a common problem sequence, helping students to master he problem that needs research.

Its module structure is designed for each chapter in the subject curriculum consisting of 13 chapters, each module has sub-modules on the content of teaching and teaching methods.

The module of Maths Teaching Methodology for teacher training colleges' students in Lao is designed in two directions: 1) Developing subject by module; each module includes sub-modules. Based on the given principle, documents according to the text module ensure the construction process with each specific step. At the same time, the document has set out a set of goals to help students have the right direction in the self-study process, there are instructions for them to easily implement self-study, self-test activities and evaluation. 2) Building documents according to digital modules including modules and sub-modules, transferred from documents according to the text module, but the difference is the ability to connect and update information quickly and effectively. The digital document module creates an overall connection of content, interesting lessons and stimulates students' interest in learning.

3.2.4. Using materials by module in teaching Maths Teaching Methodology and for Maths students in Lao teacher training colleges

\subsubsection{For students}

Method of using materials by module in teaching the module is to go from the content of learning modules that students are instructed to gradually reach the teaching goal. Each teaching content is divided into modules which has a defined goal and a testing system, students self-study and self-assess the level of mastery in terms of knowledge, skills and attitudes, so they can learn by themselves as their own pace. In addition to compiling teaching modules, teachers need to follow students during the study of the modules, helping them to concretize the knowledge, skills, answer questions, correct mistakes, and give directions, access the new module. At the end of a module, if successful, students will study the next module. If not, students need to discuss with classmates or the lecturers about difficulties, unresolved knowledge and self-research.

One of the advantages of the guiding materials by module is: 1) Personalization in learning; 2) Ensuring the formation for learners of learning chance; 3) Ensuring timely feedback to learners. However, the material has limitations. For example, compiling materials by module is quite complicated, elaborate and requires a lot of time 
from the preparation, designing and printing of finished products. Learning materials by module is suitable for a learner who is capable of learning at a certain level.

In order to use the learning materials by module effectively, students need to follow the following procedure:

Step 1. Students read the introduction about the module and its goals, preparing necessary conditions for learning (mathematical knowledge, references).

Step 2. Research the knowledge units of the module (including sub-modules). Students follow following steps: 1) Understand the goals (in terms of knowledge, skills) of the sub-module; 2) Answer the questions, self-study theory; 3) Read the pages in the document in the guide to reading the document, rechecking the accuracy of the content, which parts need supplementing, what knowledge needs research to answer the questions; 4) Do a first knowledge test yourself: The multiple-choice test consists of 5-13 questions in a period of 15-25 minutes (depending on the unit of knowledge) in order to help students test their own theoretical knowledge. The requirement of the first test is that students need to answer $81 \%$ or higher to carry out the next lesson; 5) Apply theoretical knowledge to specific exercises. If students do not know how to do the exercises, they can see the instructions at the end of each module; 6) Take the second test. Students who have successfully completed $81 \%$ or more of the second test will be transferred to the next knowledge unit (sub module) to study.

Step 3. Students do the quiz to finish the module (the test consists of 15 to 25 sentences, with testing time is from 25 to 45 minutes). When taking the test, the instructor requires students to do $81 \%$ of the test questions. If not, students study the module knowledge sections and retake the test.

Step 4. Students read the instructions at the end of each module to review any ideas that they have not mastered and continue researching the next modules.

\subsubsection{For lecturers}

Materials by modules is adapted to the content and structure of the learning program for Maths pedagogical students. At the same time, the material is also compiled in accordance with the ability of students. However, depending on the ability of each child, the effective use of materials will vary. From the content of the module, students can self-study, self-assess their level, knowledge and skills.

When using materials by module, lecturers need to change lesson plans and teaching activities during class time. In the process of organizing teaching activities, lecturers should: 1) Organize for students to discuss theoretical content, answer their questions about the contents in the lesson, supplement and conclude core important knowledge; 2) Organize for students to apply knowledge to do exercises.

Materials by modules of Maths Teaching Methodology subject can be used as references. In teaching the course, teachers can use materials by module for teaching Maths with different goals: 1) With the theoretical content of each module, teachers can use it as basic content in teaching; 2) With the system of exercises according to different levels, lecturers can choose, classify to practice for students.

In order to effectively teach the material by module in Mathematics Teaching Methodology module, based on the reality of the students' self-study process as well as the classroom teaching process of teachers, we offer two forms of using materials as follows: 1) Using materials by module for self-study completely; 2) Use traditional classroom materials with orientation to foster self-study capacity for students. With the above methods, using the module will meet the students' needs of self-study, especially each student can study at his/ her own pace as well as be able to test and evaluate himself/ herself.

3.2.5. The notes when using teaching materials by module in teaching Maths Teaching Methodology subject in Lao teacher training colleges

With lecturers, it is necessary to follow notes, including 1) Combining classroom teaching and organize selfstudy and self-study for students, organize students to discuss on topics corresponding to the content of the submodule, study the goals, the previous study task at home and organize group work in class, groups report their results; 2) Subscribing, commenting and supplementing, inculcating knowledge for students. Lecturers can assign practical exercises to students individually or in groups outside class time, then report the results to the instructor when completing the task; 3) Combining theoretical teaching in the classroom with assigning homework to students through materials by module. There is knowledge that lecturers should reduce the load in the classroom, spending time for students to research through the materials themselves, not necessarily teaching all the modules.

With students, when using teaching materials by module in learning, students need 1) Study carefully the objectives of the sub-module to understand the content of the subject; 2) Prepare all references as guided in the 
document; 3) Study carefully the content of self-study guide in the document. After collecting sufficient references, students will study the document with the focus content given in the sub-modules. After adding knowledge, students will take the test. Objective multiple-choice test to assess student self-study results. If student passes the test, they will be able to continue studying the next sub module. If not, they must return to the original module to learn again.

\section{DISCUSSION AND CONCLUSION}

With practical conditions of Lao today, it is feasible to develop and use teaching materials by module in teaching the module named Maths Teaching Methodology for students in teacher training colleges. When using materials by module, students directly learn the subject's knowledge systematically, consistent with their perceptions, stimulate excitement, study passion, especially with the following materials. The digitalized module has many advantages: students can study independently or interactively, talking with other students and lecturers to be able to solve their own questions. Students can test and assess their level of acquiring knowledge quickly, thereby adjusting learning activities accordingly.

The module document is designed according to the principles and requirements proposed by the authors, applying the theoretical views on self-study, modules and teaching modules, exploiting the strengths of the teaching module. Using materials by module can support the classroom teaching process and the process of renewing teaching methods at pedagogical colleges. The methods of using materials according to module in Maths teaching methodology proposed by the article such as using materials by module to fully self-study, using materials by module in the traditional classroom have met requests for self-study and support the self-study activities of students in Lao teacher training colleges.

\section{REFERENCES}

Bun Suoi, Chit Ta Vong \& Movie Ma Son (2009). Maths Teaching Method for subject Mathematics 1 for students in Lao teacher training Colleges. Education Publishing House, Vientiane, Lao.

Cruchetxki V. A. (1981). The foundations of pedagogical psychology (Vol. 1, 2). Vietnam Education Publishing House, Hanoi, Vietnam.

Espiritu (1980). Social Foundation of Community Development. Carcia Publishing House, Manila, Philippines.

Havinghurst R. S. (1973). Human Development and Education. Longmans Green, New York, USA.

Jab Vongthavy (2014). Applying some teaching methods to actively improve student learning in Analytics teaching in Lao teacher training college. Doctoral Thesis in Educational Science, Hanoi National University of Education, Hanoi, Vietnam.

Kham Khong SiBuna Kham (2010). Positive teaching methods, exploiting teaching methods to improve positively Algebra and Analytics learning activities of high school students of Lao. $\mathrm{PhD}$ Thesis in Educational Science, Hanoi National University of Education, Hanoi, Vietnam.

Khambau Sangouantrichanh (1981). Applying the viewpoint of activities and differentiating students in improving the Maths teaching method through title Equation in Lao high schools' final grade. PhD Thesis in Educational Studies, Hanoi National University of Education, Hanoi, Vietnam.

Kharlamop, I. F. (1978). How to promote students' learning activeness? Vietnam Education Publishing House, Hanoi, Vietnam.

Lao Ministry of Education and Sports (1997). Materials for training Maths teachers of middle and high school. Lao. Nguyen Ba Kim (2015). Maths Teaching Methodology. University of Education Publishing House, Hanoi, Vietnam. Nguyen Quang Uan (2010). Research Collection on Psychology - Education. University of Education Publishing House, Hanoi, Vietnam.

Phan Trong Ngo (2005). Teaching and teaching methods in schools. University of Education Publishing House, Hanoi, Vietnam.

Tran Duc Khoan (2017). Building and using teaching documents by module with guidance in Physics subject contribute to fostering self-study capacity for university students in technics. PhD Thesis in Educational Science, Vinh University, Nghean province, Vietnam. 